\title{
O CORPO COMO COMPONENTE DAS FORMAS DE PARTICIPAÇÃO DAS CRIANÇAS NA EDUCAÇÃO INFANTIL
}

\author{
El cuerpo como componente de las formas de participación \\ de los niños en la educación infantil
}

\section{The body as a component of the forms of children's participation in early education}

\author{
KÁTIA ADAIR AGOSTINHO*1 \\ http://orcid.org/0000-0003-0261-9790 \\ *Universidade Federal de Santa Catarina. Brasil. \\ Correspondencia: katia.agostinho@ufsc.br
}

Recibido: 06-11-2017

Revisado: 30-11-2017

Aceptado: 15-01-2019

\begin{abstract}
Resumo: O estudo, uma pesquisa etnográfica com crianças, com o objetivo de conhecer suas formas de participação na educação infantil (identificou a forma intensa e pulsante com que seu corpo participa em seus contextos educativos expressando seus pontos de vista. A partir da empiria e bases teóricas (Ferreira, 2009, 2013; Fingerson, 2009; Gil, 1997; Le Breton, 2009) vimos que o corpo das crianças está na base de toda sua experiência social, mediador das relações, das práticas, dos discursos, das apropriações do Outro e do mundo. Tal ideia precisa ser considerada nas práticas pedagógicas para que respeitemos 0 corpo da criança ávido por descobrir e descobrir-se na sua relação novidável e embrionária com o mundo.
\end{abstract}

Palavras-chaves: corpo; criança; direitos; educação infantil; prática pedagógica.

Resumen: El estudio, una investigación etnográfica con niños, con el objetivo de conocer sus formas de participación en la educación infantil identificó la forma intensa y pulsante con que su cuerpo participa en sus contextos educativos expresando sus puntos de vista. A partir de la empiria y las bases teóricas (Ferreira, 2009, 2013; Fingerson, 2009; Gil, 1997; Le Breton, 2009) vimos que el cuerpo de los niños está en la base de toda su experiencia social, mediador de las relaciones, de las prácticas, discursos, de las apropiaciones del Otro y del mundo. Tal idea necesita ser considerada en las prácticas pedagógicas para que respetemos el cuerpo del niño ávido por descubrir y descubrir en su relación noble y embrionaria con el mundo.

Palabras clave: cuerpo; niños; derechos; educación infantil; práctica pedagógica.

Abstract: The study, an ethnographic research with children, aimed at knowing their forms of participation in early childhood education identified the intense and pulsating way in which their body participates in their educational contexts expressing their points of view. From the empiria and theoretical bases (Ferreira, 2009, 2013; Fingerson, 2009; Gil, 1997; Le Breton, 2009) we have seen that the children's body is the basis of all their social experience, mediator of relationships, practices, discourses, the appropriations of the Other and the world. This idea must be considered in pedagogical practices so that we respect the body of the child eager to discover and discover in its new and embryonic relationship with the world.

Keywords: body; child; rights; early education; pedagogical practice.

1 Doutora em Estudos da Criança pela Universidade do Minho/Portugal, mestre em Educação pela Universidade Federal de Santa Catarina, licenciada em História. Linhas de trabalho: educação, infância, criança, formação de professores. 


\section{PALAVRAS INICIAIS}

As discussões aqui tecidas partem de um estudo, em nível de doutorado (Agostinho, 2010), sobre a participação das crianças nos contextos de sua educação, em que realizei uma pesquisa etnográfica, numa pré-escola pública, com 33 crianças $^{2}, 18$ meninas e 15 meninos, de 3 a 6 anos, 1 professor e 1 professora esporádica, ao longo de 2 anos, e que tem, como princípio fundador, um projeto emancipatório que contribua para uma sociedade democrática, solidária e com justiça social. Neste texto abordarei sobre os modos pelos quais as crianças participam de corpo inteiro na pré-escola.

Para realizar a investigação segui os preceitos de uma etnografia com crianças profícuo caminho metodológico para conhecê-las, que permite observar diretamente a participação delas em atividades diárias e registrar interações significativas entre elas e com os adultos, na busca de compreender os sentidos dados pelos sujeitos investigados. Em uma temporalidade densa -imensurável e não linear-, com a necessária reflexividade do pesquisador, o consentimento sistemático e contínuo dos partícipes da pesquisa e da escrita etnográfica, que partilha a interpretação do pesquisador e convida ao diálogo.

Pela complexidade da temática — seus desafios, contradições, impasses e paradoxos teóricos, sociais e políticos-, é importante manter atenção ao alerta de Fulvia Rosemberg para o fato de que na expansão da condição de cidadania, entre aqueles que ocupam os lugares de subgrupos humanos, as crianças constituem um dos últimos grupos, se não o último, a terem seus direitos reconhecidos (Rosemberg, 2012). Tal situação se agrava quando nos detemos nos direitos de participação, sendo os que se referem ao status de sujeito das crianças bem mais relevantes (Qvortrup, 2010). Essa complexidade é acrescida ainda da singularidade com que as crianças concretizam e expressam o seu processo de participação na vida social e na construção da própria infância.

Ao realizar o estudo, o corpo das crianças apareceu como grande informante de seus modos próprios geracionais de participar. Os novos enfoques da pesquisa sobre a infância dão grande relevância às crianças como ativas na vida social, mas "muitas vezes não conseguem perceber a importância da corporificação nos processos por meio dos quais as crianças participam da vida social" (James, Jenks e Prout, 1999, p. 209), evidenciando a necessidade de compreendermos o seu corpo e o papel que desempenha nas relações sociais.

Contudo, nos últimos anos, o corpo das crianças já vem aparecendo na reflexão teórica em nossa área no Brasil. Outras pesquisas (Guimarães, 2008; Coutinho, 2010; Arenhart, 2012; Buss-Simão, 2012) realizadas com crianças na educação infantil

\footnotetext{
${ }^{2}$ As autorizações para a pesquisa e fotografias foram dadas pelos familiares e pelas crianças durante todo o processo de investigação em uma perspectiva de consentimento em processo.
} 
também trazem contributos para o pensarmos, inserindo-o em discussões que relegam o reducionismo biológico e a dissolução do corpo como ente material, carnal. Assim,

$\mathrm{Na}$ interseção da relação e da praxis, da linguagem e do símbolo, da instituição e da contestação, da percepção e da ação, da sensação e da emoção sobre o mundo, o corpo acaba por assumir, em termos sociológicos, não apenas o estatuto epistemológico de objeto de poder, mas também de locus de ação (Crossley, 1996, p. 104; Frank, 1995 [1991], pp. 48-49). Daí a necessidade de trazer não só a carnalidade à sociologia, como de repensá-la de uma forma ativa, entendendo o corpo na sua concretude, não apenas como produto de estruturas sociais e culturais, mas também como agente social, como ator e enjeu (Berthelot, 1987, p. 7), como operador social ativo (Crossley, 1996, p. 99). (Ferreira, 2013, p. 522. Grifos do autor).

\section{O CORPO DAS CRIANÇAS}

Sobre o corpo das crianças recai um número significativo das marcas identitárias do pensamento das sociedades ocidentais daquilo que se caracteriza ser criança: sua estatura, vulnerabilidade, destreza, capacidade, forma, elementos que as próprias crianças reconhecem como marca identitária da infância, um episódio de campo dá visibilidade ao exposto:

Margherita vem e me enche com seu bem querer: me abraça, beija, massageia. Rimos juntas e conversamos, aproveito e pergunto a ela:

Pesquisadora: _ Marg, me diz o que para ti é uma criança?

Margherita:_Criança é o Mário! E aponta o menino.

(Registro de campo, 11/03/09).

Margherita ${ }^{3}$ dá a Mário o sentido do que é ser criança para ela; na corporeidade do menino, a menina encontra muitos dos sentidos para essa escolha, ele é um menino de 3 anos que acaba de chegar ao grupo e pertence aos menores em idade e estatura da sala, ela tem 5 anos e está no grupo há 3 anos, a estatura, forma, destreza, capacidade que o corpo do menino revelam são os aspectos que a menina utiliza para aferir o que é uma criança.

Sabemos que não mora na corporeidade de todas as crianças do mundo esta compreensão, estudos com populações indígenas dão visibilidade a outros modos de identificar a criança e a infância, "o que é ser criança, ou quando acaba a infância, pode ser pensado de maneira muito diversa em diferentes contextos socioculturais" (Cohn, 2005, p. 22).

\footnotetext{
${ }^{3}$ Os nomes das crianças são verdadeiros por opção das mesmas e devidamente autorizados.
} 
Como um dos elementos identitário da infância e da criança ocidental o corpo das crianças carrega em sua materialidade a sua condição geracional, sendo o seu inacabamento um dos signos no qual, historicamente, se fundamentam muitas das ideias sobre a percepção delas como infant.

Seu corpo está "inacabado" no nascimento e só será "concluído" por meio de ação na sociedade. "O filhote do homem necessita ser reconhecido pelos outros como um ser existente, para poder se estabelecer como sujeito" (Le Breton, 2009, p. 15). É durante a infância que esse processo de "acabamento" do corpo é intenso. Explodem rápidas e significativas mudanças corporais, no peso, estatura e agilidade. Precisamente porque o corpo da criança é caracterizado por mudanças biológicas aceleradas, a incorporação delas será muito diferente da dos adultos.

No corpo - um objeto a conhecer e meio de conhecimento- estão os híbridos que constituem nossa humanidade, lugar em que se encontram, mesclam naturezacultura, corpo-mente, razão-emoção, ação-estrutura etc. Através dele podemos vencer os dualismos recorrentes na tradição moderna, (re)conhecer as formas de poder que o social imprime na natureza e o modo como são socializados e/ou explorados socialmente os recursos, capacidades e atributos que lhe são naturais.

"O corpo é o lugar de soberania do sujeito, é a primeira matéria da sua ligação com o mundo" (Le Breton, 2004, p. 16), sendo que o das crianças apresenta-se, geralmente, com um grande ímpeto para se relacionar com o mundo, com vivacidade e energia. Ao participarem de corpo inteiro nos seus contextos, as crianças visibilizam a natureza incorporada/corporificada da ação humana, realizada por pessoas reais, vivas e corpóreas, nos apontando a necessidade de não negligenciarmos essa forma de sua participação.

O corpo é experimentado, gerido e compreendido socialmente. O corpo é uma fonte direta de agência e pode ser como uma fonte de agência e poder em interação social. Para crianças e adolescentes, em especial, o corpo é saliente em suas vidas e afeta sua interação social. A fim de compreender verdadeiramente a vida das crianças, devemos compreender suas vidas incorporadas (Fingerson, 2009, p. 226).

Para o corpo infantil é direcionado um conjunto de sonhos e desejos: de juventude, agilidade, desenvoltura. Esses mesmos atributos também são alvos de recriminações quando se expressam em espaços e tempos que os adultos julgam inadequados, recaindo sobre eles, nesses momentos, limitações e proibições. Paradoxalmente, sua materialidade comporta o sonho de continuidade e vivacidade ao mesmo tempo em que sustenta a exigência de comportamento e domesticação. 


\section{O CORPO DAS CRIANÇAS PARTICIPA - SEU CORPO COMUNICA SEUS PONTOS DE VISTA}

Compreender a comunicação é também compreender a maneira como o sujeito, de corpo inteiro, nela participa (Le Breton, 2009, p. 40).

A veemência do corpo das meninas e meninos com que me encontrei fez com que considerasse que a primeira e mais contundente informação do estudo é que seu corpo - seus movimentos e expressões - é meio de comunicação potencialmente informante das formas de participação das crianças, e que por meio dele elas expressam seus pontos de vista. Esta constatação corrobora com a perspectiva de democracia comunicativa de Iris Young (1997), que reconhece os aspectos não linguísticos da comunicação —nem todas as pessoas têm as mesmas condições e nem utilizam as mesmas vias de comunicação, podendo expressar de vários modos os seus pontos de vista.

O modo das crianças se relacionarem com o mundo físico e social daquela préescola foi fluido, em movimento de ser e estar, construindo assim suas relações com e através de seu corpo, com pequenos e grandes movimentos, gestos e expressões, acentuando assim a vertente do corpo na comunicação que corporifica a relação com os outros (Le Breton, 2009).

Os inumeráveis movimentos corporais (gestos, mímicas, posturas, deslocamentos etc.) empregados nas interações oferecem ao discurso uma corporeidade que lhe acrescenta significações. É o corpo, nas suas atitudes e posturas, que primeiramente evidencia a presença do outro na interação. $O$ corpo é parceiro homogêneo da língua na "permanente circulação de sentido, a qual consiste na própria razão de ser do vínculo social —O movimento do corpo metaforiza a palavra. Nenhuma palavra existe independentemente da corporeidade que lhe envolve e lhe confere substância" (Le Breton, 2009, p. 42).

As ações na vida cotidiana envolvem a mediação do corpo, que constitui "uma base concreta e material, viva, vivida e em devir, que informa a construção de relações que são culturalmente potencializadas" (Ferreira, 2009, p. 3), sua comunicação é um processo dotado de múltiplos canais. O sistema global de comunicação inclui a gestualidade, a mímica, as posturas, a língua, os silêncios, a tonalidade da voz. Incide, ainda, sobre o corpo, como canal comunicacional, a distância com que são travadas as interações, a relação com o espaço e com o tempo.

Considero que a sequência fotográfica abaixo (Figura 1) ajuda a perceber o potencial comunicante do corpo das crianças. Nela podemos acompanhar uma conversa entre Giulia, Giorgia e Margherita, todas com 4 anos de idade e 2 anos de vivência no grupo. Elas estão sentadas num canto da sala, onde estão elementos da casinha de bonecas. Sobre a mesa vemos alguns deles, e nas mãos de Giorgia, uma boneca: 
Giulia, Giorgia e Margherita conversam envolvidamente sobre muitos assuntos: lugares onde vão, praias, sons, som de cavalo etc. Ao interagirem naquela roda de conversa as meninas fazem muitas expressões. Ao explicitarem o seu ponto de vista, apoio, dúvida e/ou sua contrariedade à ideia da outra, a expressão vinca-se, incrusta-se com mais força e veemência em suas faces. Por vezes, seus corpos levantamse da cadeira e suas vozes aumentam de tom na defesa de suas posições (Registro de campo, 13/06/08).

Figura 1: Sequência fotográfica 1 - 13/06/08
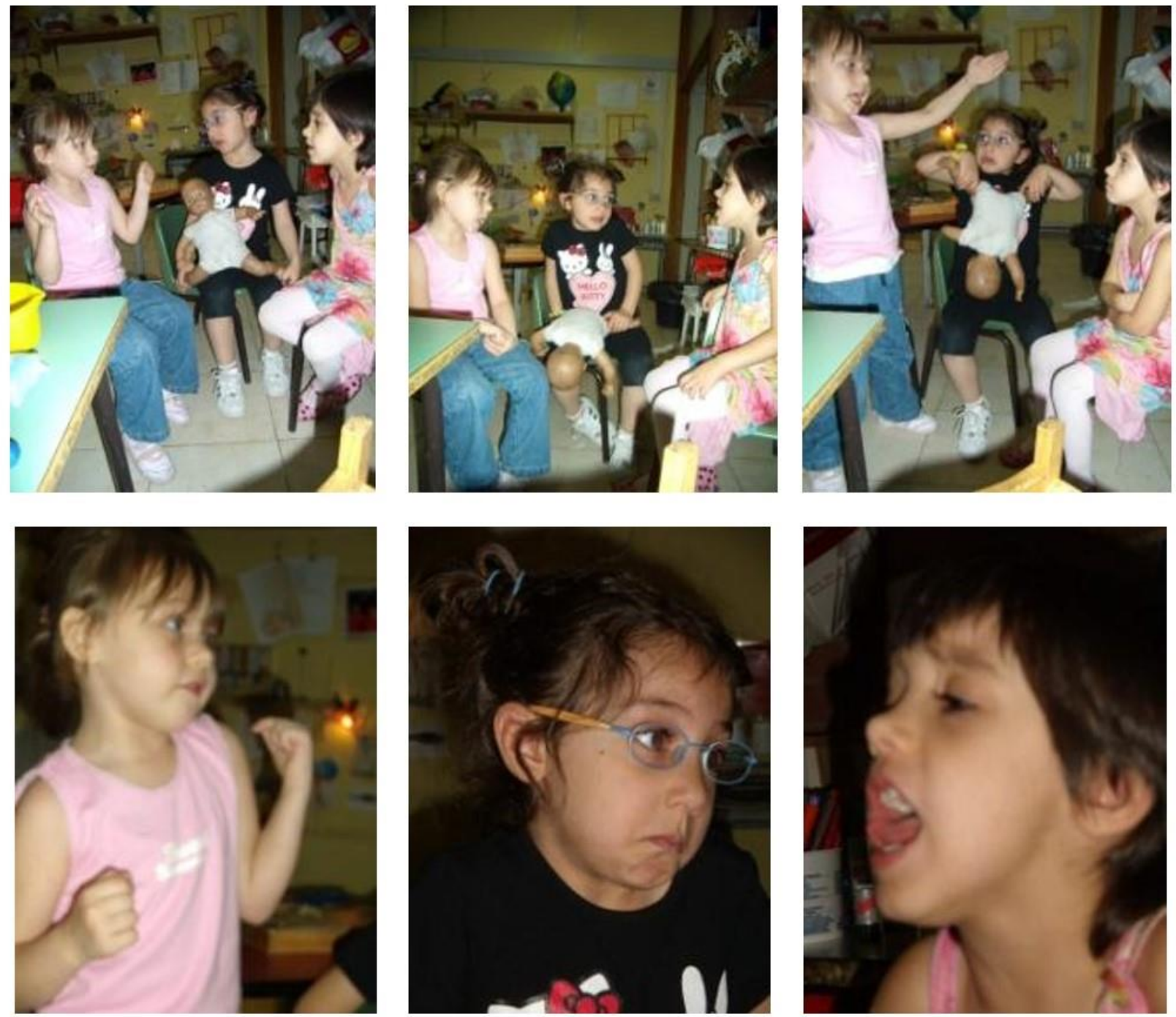

Fuente: Elaboración propia (2008)

Assim sendo, os movimentos, gestos, expressões e posições das meninas, inscrevem numa forma simbólica do espaço e do tempo, uma simbologia de rostos e corpos, um 
uso característico da palavra. Todos esses elementos constituem-se importantes informantes do que as meninas pensam, sentem e de como agem no mundo e estruturam suas relações. Esse emaranhado complexo de formas comunicacionais demonstra que a interação solicita múltiplos canais, que cada pessoa explora de acordo com suas particularidades e estilo com seus pares.

As crianças como atores sociais de direitos próprios são sujeitos de conhecimento e produtoras de sentido de corpo inteiro, são legítimas suas formas de comunicação e relação, assim contribuem para a renovação e reprodução dos laços sociais nos espaços em que participam. O corpo da criança, como suporte para a sua ação social, expressa saberes, dúvidas, aceitação, contraposição, sentimentos, fragilidades, força, agilidade, incapacidade, fraqueza, enfim, seus pontos de vista, nos informando, dessa maneira, os modos de ser criança das meninas e meninos.

Viver, experienciar e expressar seu e através do corpo é importante para as crianças. Durante as observações em presença e as análises dos registros escritos e fotográficos a intensidade com que elas viviam seu corpo —indo de cá para lá, dançando, correndo, escorregando, baixando, pulando, puxando, empurrando, subindo, levantando, deslizando, equilibrando, gesticulando etc.- chama ao reconhecimento de que nele a vida irrompe, velozmente cresce e modifica-se num corpo que vai adquirindo destreza ao explorar e explorar-se em inter(ação).

Tal consideração não ignora o fato de que nem todas as crianças o fazem do mesmo jeito. Não reside sobre todos os corpos infantis o mito da vivacidade. Desse modo, não é possível corroborar com o imaginário mitificador do corpo ágil que habita todas as crianças, já que essa ideia comum veiculada não encontra ressonância na realidade. Existem crianças para as quais, por escolha ou limitações, a expressão e a experiência de seu corpo, seus movimentos e gestos, são mais contidos, moderados, em alguns momentos quase imperceptíveis, outras ainda com deficiências que limitam o corpo de modo passageiro ou para sempre. As crianças são diferentes entre si, e seu corpo e a forma de expressá-lo também.

Ao participarem de suas rotinas cotidianas as crianças expressavam a todo momento seus modos de ser e interagir com o mundo no e com seus corpos, que também são conhecimento e sentido prático. Suas percepções, intenções e ações, nas diferentes relações estabelecidas, marcavam-se em suas expressões, ricas comunicantes de seus pontos de vista. Então, "Que enigmas e revelações pode um rosto desvendar? -No fundo, o rosto é um lugar geométrico de conhecimento" (Pais, 2006, p. 15). Pergunta e resposta nos ajudam a refletir sobre o potencial das expressões das crianças como elementos de sua participação. 
Figura 2: Fotos em datas diferentes em 2008 e 2009
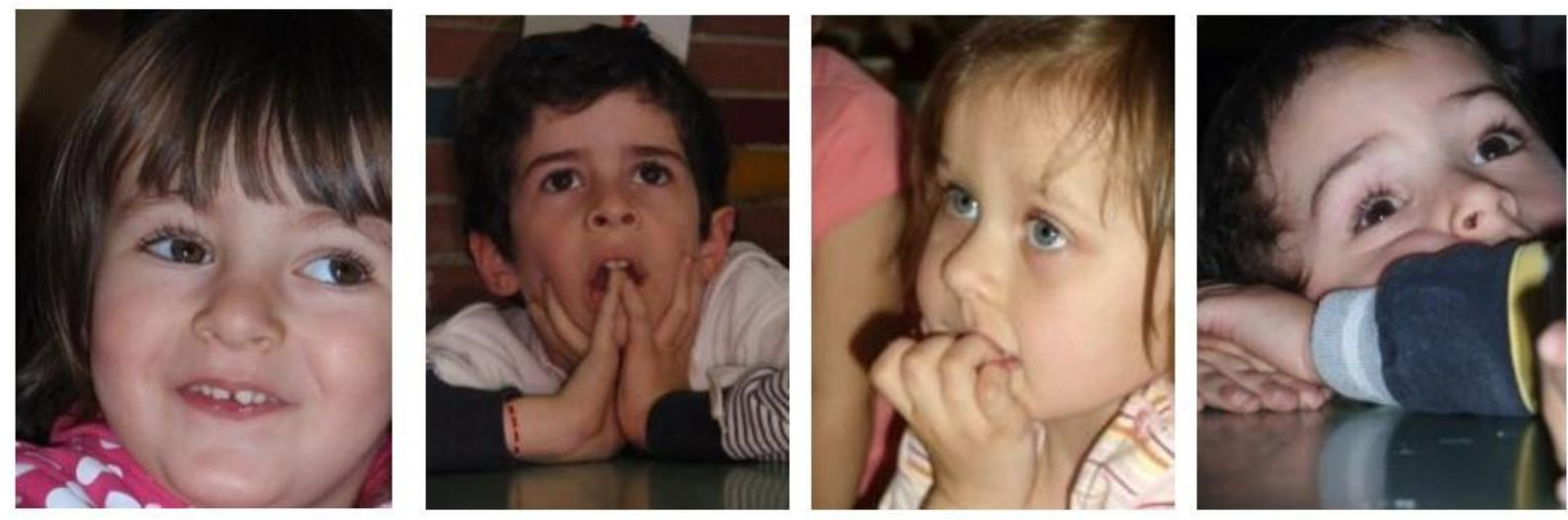

Fuente: Elaboración propia (2008, 2009)

$\mathrm{Na}$ expressão das crianças que vemos nas fotos "boca, olhos, ouvidos e, em menor grau, o nariz, formam um complexo de órgãos sensoriais que, pela sua disposição (simétrica e à volta da cabeça), induzem um "centro» de onde vem e para onde vai o sentido da comunicação" (Gil, 1997, p. 167). Cada sujeito situa, mais provavelmente, o seu eu no espaço de onde olha, ouve e se ouve a si próprio. Sendo assim, o rosto sustenta a identidade pessoal. Nele, o olhar e a expressão na trama simbólica da interação cumprem um importante papel, eles contribuem para o desenrolar da interação, os olhos recebem e simultaneamente transmitem informações na troca de enunciados, as expressões comunicam diferentes conteúdos.

Ao estabelecerem as diversas relações que se cruzavam naquele espaço educativo, as crianças, sujeitos da comunicação e percepção, situavam-se na zona fronteiriça entre o interior e o exterior, no espaço de limiar. É nele —em síntese, toda a pele que envolve toda a superfície corporal-que acontece nossa relação com o mundo. É na pele e com ela que estabelecemos nossa comunicação com o mundo, ela é a abertura do corpo ao corpo do outro e a consequente conexão afetiva-cognitiva que se estabelece. Gil (1997) nos fala da vocação da pele para a inscrição: "a sua cor, a sua textura, a sua situação no corpo tornam-na um meio privilegiado para inscrever todo 0 tipo de mensagens, quer dizer, um meio único de comunicação" (p. 181).

O corpo das crianças, todo ele (movimentos, gestos, expressões, olhares), como espaço do limiar, é a superfície com que inscreve sua ação diante da estrutura e onde a estrutura inscreve os códigos de sociabilidade eleitos socialmente. Ao entendermos como as crianças experienciam seus corpos, podemos apreender aspectos mais amplos de seus cotidianos, como aponta Fingerson (2009), ao afirmar que os indivíduos são constrangidos pelas condições em que vivem, e "é através dos seus corpos, através de suas práticas corporais, que podem tornar-se sujeitos, participar na construção dessas condições, transcender essas condições e agir de acordo com seus mundos" (p. 217). 


\section{O CORPO DA CRIANÇA E SUA INCORPORAÇÃO NA PRÉ-ESCOLA}

A presença e participação do corpo infantil, ávido por descobrir e descobrir-se na sua relação novidável e embrionária com o mundo, interrogam as práticas pedagógicas em creches e pré-escolas, através de sua incessante comunicabilidade, de modo que possamos refletir - que corpos de meninos e meninas de 0 a 6 anos estamos construindo?

O corpo das crianças é objeto de controle e regulação intensos por parte das instituições educativas que tendem a assegurar a conformidade das crianças às normas da ordem estabelecida com práticas de disciplinamento e uniformização, colocando limites e efetivando sanções na moldagem e construção de um corpo que corresponda a ideais e expectativas adultocêntricas. No corpo da criança reside um conjunto de componentes físicos em plena constituição. Nele a vida explode, e aparece com força a vontade de desbravar e se aventurar. O irromper da vida, com sua força e velocidade, interroga a estrutura que tende a formatar, paralisar, enrijecer, docilizar, disciplinar.

Figura 3: Sequência fotográfica 2 - 10/03/09
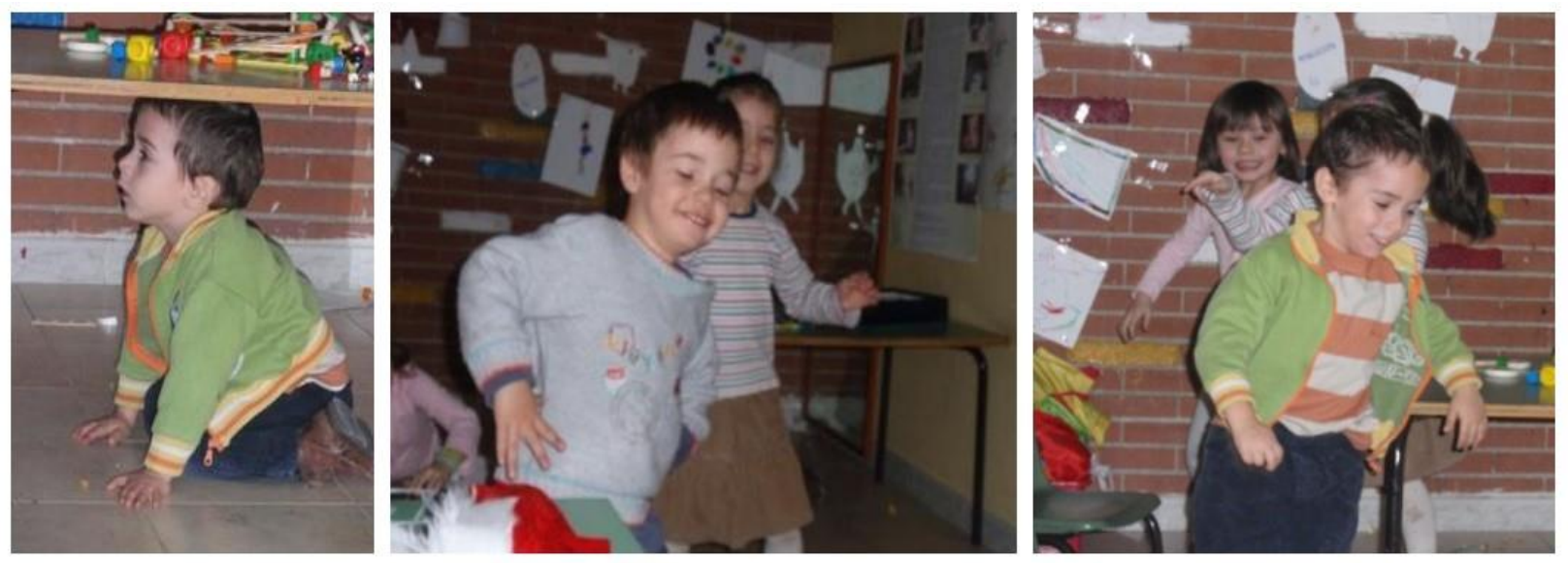

Fuente: Elaboración propia (2009)

Essa sequência de fotografias (Figura 3) é assim descrita no registro do diário de campo:

Chiara, com a caneta de raio laser nas mãos, vai jogando a luz e brincando com Cristiano e Tomaso. Giulia se aproxima e também se envolve na brincadeira, eles riem. Chiara faz cócegas nos meninos, eles retribuem com sorrisos e tentativas de também fazer nela, juntos se divertem. Cristiano sai correndo pela sala e Tomaso o segue, Cristiano vai para debaixo da mesa e Chiara já está correndo atrás de Tomaso. Cristiano sai debaixo da mesa e junta-se a eles assim como Giulia. (Registro de campo, 10/03/09). 
O sorriso e o prazer expressados pelas crianças na vivência dessa corrida pela sala são claros e contagiantes. A forma fluida e despreocupada com que meninas e meninos 0 fazem nos ajuda a perceber a presença de corpos que expressam a vontade de movimento, aventura, experimento, de conhecer e conhecer-se, sem que necessariamente estejam confrontando o estabelecido pelas regras adultas, por exemplo, de que não se pode correr na sala. Seus diferentes movimentos ao participarem nas rotinas diárias da pré-escola indicam sua disposição para conhecer o mundo e a si mesmo, sua capacidade e força. Importa aqui trazer para o debate a presença dessas expressões de modo que possamos aprofundar nossa reflexão e conhecimento sobre as mesmas, para que possam ser questionados os modos controladores e limitantes que se impõem nos espaços educativos sobre as vivências do corpo das crianças.

Era clara a necessidade que as crianças tinham de viver e expressar seu corpo. Os desafios que a elas se apresentavam de controlarem essa expressão, pelo menos no que tange aos movimentos amplos, nos momentos em que o tempo e o espaço não eram para sua expressão, colocam importantes reflexões. Segundo Berry Mayall (1996), para as crianças, o poder na relação com os adultos limita sua capacidade de fazer um lugar e um espaço para a sua própria incorporação.

A infraestrutura da sala colocava constrangimentos e limitações às possibilidades de as crianças se movimentarem e poderem praticar toda sua expressão corporal. A sala compreendia trinta e cinco metros quadrados, com sete mesas, cadeiras, armários, estantes, brinquedos, jogos e materiais por todas as laterais, somando, ainda, as pessoas que ali habitavam: crianças e professores sistematicamente; familiares e amigos em momentos pontuais. Esses fatos são comumente encontrados nos espaços de educação. Os movimentos mais amplos das crianças eram contidos e constrangidos por um espaço exíguo, bem como pela responsabilidade e preocupação do professor com o bem-estar e proteção delas. As crianças viviam esses constrangimentos na expressão de seus movimentos de forma diferenciada no tempo e entre si.

A ação e participação das crianças que interrogam e reinscrevem a estrutura, também a estrutura que as força e as constrange a limitações e adaptações a um conjunto de regras socialmente eleitas, visibilizam a complexidade que se instaura nas redes de relações e forças que se cruzam na cotidianidade educativa e nos exige atenção em tê-las em conta.

Assim, é imprescindível o desenvolvimento de abordagens adequadas às formas de comunicação pelas quais as crianças expressam seus pontos de vista, numa cultura de comunicação que comece a partir da posição da criança, reconhecendo as suas diferenças, a fim de que possamos construir práticas democráticas, estabelecidas no paradigma da escuta, mais especificamente da ausculta, implicadas na comunicação humana.

As ações na vida cotidiana envolvem a mediação do corpo, que constitui uma base concreta e material, viva e vivida, na qual podemos nos inspirar na ideia de que 
não há limite para o conhecimento, para a ação, para a experiência que só têm sentido para as crianças quando atravessam o corpo (Benjamin, 1928/1992). E assim foi, das observações realizadas e dos materiais coletados, a constatação mais fácil e rápida é a de que viver, experienciar e expressar seu corpo é importante para as crianças. Isso compreendido pela contundência, pulsação, vivacidade e movimento com que elas viviam e o expressavam.

Enquanto profissionais, responsáveis pelo seu bem-estar, compreendo a importância de mantermos o cuidado e a atenção quanto às necessárias medidas de proteção das crianças. Importante aqui é aprender um modo de manter essa tensão, essa ambivalência em equilíbrio. Entendo, ainda, que devem ser convocadas aprendizagens e posturas que tenham a sensatez e o discernimento para a vida em sociedade, baseadas no respeito e na partilha com o Outro, como parte de processos de aprendizagens sociais e culturais. Podemos aqui, além de manter a tensão em equilíbrio entre autonomia e proteção, liberdade e disciplina, pensar em instaurar um tempo de aprendizagens mútuas e, assim, acentuar os sentidos de interdependência.

Nas práticas pedagógicas é importante a atenção ao equilíbrio entre a garantia da possibilidade de expressão de seu corpo e —reconhecendo as crianças como indivíduos novos na convivência coletiva - e a instauração, com sensibilidade, sutileza e bom senso, de processos de iniciação nos modos próprios das formas societais de expressão e vivência do corpo.

A contundência com que o corpo foi vivido e experienciado pelas crianças nos faz refletir acerca das ações que questionam a ordem comumente estabelecida do disciplinamento do corpo, da obediência que deseja corpos silenciosos, rijos, dóceis, colocando para nós o desafio e o empenho por construir corpos desbravadores, flexíveis, fluidos e críticos. As crianças ao moverem-se, expressavam seus modos de participar das rotinas daquele espaço educativo, tanto naquelas estruturadas por elas, quanto naquelas estruturadas, organizadas, planejadas, direcionadas pelo professor.

No processo educacional, geralmente, as crianças são guiadas a se conformarem com os padrões de atividade corporal —eleitos como adequados às situações comunsincorporando, assim, uma linguagem do corpo, um código de estilos que devem seguir normas e conveniências. Tem-se o corpo, então, como o destinatário das práticas educacionais do controle, da repressão e do castigo. Ficam os indicativos das crianças pesquisadas para que práticas diversas se instaurem.

Sensibilidade e perspicácia adulta são necessárias, precisam ser ativadas e cultivadas para que, atentos ao potencial informante acerca das crianças em suas expressões e pequenos gestos, possamos apreender deles importantes elementos que nos mostram suas formas de pensar e participar nas ordens sociais do contexto préescolar. 


\section{PALAVRAS FINAIS}

A defesa da democracia comunicativa inscrita na ética do cuidado e da solidariedade para com o Outro reconhece a diferença e favorece a pluralidade, ampliando as possibilidades de práticas democráticas inclusivas e enriquecendo as práticas pedagógicas na educação infantil nos seus princípios éticos e políticos.

Ao dar visibilidade ao corpo das crianças - com sua comunicabilidade híbrida (natureza/cultura, corpo/mente, razão/emoção etc.) que a todo momento vai dando as pistas, comunicando suas formas de pensar, sentir o mundo que a rodeia- defendo sua potência como elemento constitutivo da participação das crianças em suas vidas cotidianas, podendo prover pistas e inspiração para pensar e praticar essa participação nos contextos de educação da infância.

Nas formas próprias das crianças participarem, de expressarem seus pontos de vista, de maneira vívida e pulsante, utilizando-se do sistema global de comunicação, elas vivem o confronto com os constrangimentos sociais em presença, instaurando um espaço de negociação em que a ação e a estrutura se encontram e forjam a complexidade da realidade. Dependerá da força de uma e de outra o resultado do lado para o qual penderá a balança.

Importa, sobremaneira, construir uma ética comunicativa sem priorizar as vias ocidentalmente consagradas da fala e da escrita. Para isso, precisamos ativar deliberada e conscientemente a sensibilidade, a astúcia e a perspicácia para compreender as diferentes formas como as crianças expressam seus pensamentos e sentimentos, além de apreender a complexidade da participação das crianças em suas rotinas educativas, sua multidimensionalidade, tendo em vista nosso reconhecimento da presença e da importância de todas as dimensões do humano.

As crianças, sendo atores sociais de corpo inteiro, expressam nas maneiras como vivem com e através do seu corpo suas formas de participar dos seus mundos de vida. Suas experiências são vividas por um corpo que existe de fato, vivo e indivisível entre o sujeito e a sua carne, ultrapassando as dualidades enraizadas no pensamento sobre 0 corpo. É importante compreender o que os seus corpos nos contam de sua pertença geracional, dos seus modos próprios de participar nos seus contextos de educação, em que produzem e reproduzem cultura com os seus pares e com os adultos, num e com um corpo vivido de um sujeito que experimenta e produz o mundo social.

Uma das questões centrais para a construção de uma pedagogia para a educação infantil é aquela que diz respeito ao lugar que temos destinado ao corpo das crianças, suas vivências e experiências. É importante pensar e organizar tempos e espaços de possibilidades de vivencia rica, plural, aventureira e fluida em que as crianças possam expressar e experimentar seus corpos nas creches e pré-escolas, uma pedagogia que "precisa resistir bravamente a todas as formas de hierarquia, dominação e poder para que conquistemos o estatuto de cidadãos" (Sayão, 2008, p. 7). 


\section{REFERENCIAS}

Agostinho, K. A. (2010). Formas de Participação das Crianças na Educação Infantil (Tese de doutoramento). Universidade do Minho, Portugal. Disponível em https://repositorium.sdum.uminho.pt/bitstream/1822/11195/1/Tese.pdf

Arenhart, D. (2012). Entre a favela e o castelo: efeitos de geração e classe social em culturas infantis (Tese de Doutorado). Universidade Federal Fluminense, Brasil.

Benjamin, W. (1992). Rua de sentido único e Infância em Berlim por volta de 1900. Lisboa, Portugal: Relógio D'água Editores.

Buss-Simão, M. (2012). Relações sociais em um contexto de educação infantil: um olhar sobre a dimensão corporal na perspectiva de crianças pequenas (Tese de Doutorado). Universidade Federal de Santa Catarina, Brasil.

Cohn, C. (2005). Antropologia da Criança. Rio de Janeiro, Brasil: Jorge Zahar.

Coutinho, Â. M. S. (2010). A ação social dos bebês: um estudo etnográfico no contexto da Creche (Tese de Doutoramento). Universidade do Minho, Portugal.

Ferreira, V. (2009, novembro). Elogio (sociológico) à carne: A partir da reedição do texto 'as técnicas do corpo' de Marcel Mauss. Conferência no lançamento da Colecção Arte e Sociedade. Universidade do Porto, Portugal.

Ferreira, V. (2013). Resgates sociológicos do corpo: Esboço de um percurso conceptual. Revista Análise Social, 48(208), 494-528.

Fingerson, L. (2009). Children's Bodies. En J. Qvortrup, W.A. Corsaro \& M. Honig (Ed.), The Palgrave Handbook of Childhood (pp. 217-227). Hampshire: Palgrave Macmillan.

Gil, J. (1997). Metamorfoses do corpo. Lisboa, Portugal: Relógio D’Água.

Guimarães, D. O. (2008). Relações entre adultos e crianças no berçário de uma creche pública na cidade do Rio de Janeiro: técnicas corporais, responsividade, cuidado (Tese de Doutorado). Pontifícia Universidade Católica do Rio de Janeiro, Brasil.

James, A., Jenks, C., e Prout, A. (1999). O corpo e a infância. Em W. Kohan, \& D. Kennedy, Filosofia e Infância: Possibilidades de um encontro (pp. 207-238). Petrópolis, Brasil: Vozes.

Le Breton, D. (2004). Sinais de indentidade. Tatuagens, piercings e outras marcas corporais. T. Frazão (Trad.). Lisboa, Portugal: Misótis.

Le Breton, D. (2009). Paixões ordinárias. Petrópolis, Brasil: Vozes.

Mayall, B. (1996). Children, health and the social order. Bristol, Inglaterra: Open University Press.

Pais, J. M. (2006). Nos Rastos da Solidão. Deambulações Sociológicas. Enciclopédia Moderna Sociologia. Porto, Portugal: Ambar.

Qvortrup, J. (2010). Infância e política. Cadernos de Pesquisa, 40(141), 777-792. 
Rosemberg, F. (2012). A criança pequena e o direito à creche no contexto dos debates sobre infância e relações raciais. In M. A. Silva Bento (Org.), Educação infantil, igualdade racial e diversidade: aspectos políticos, jurídicos, conceituais (pp. 11-46). São Paulo, Brasil: Centro de Estudos das Relações de Trabalho e Desigualdades/CEERT.

Sayão, D. (2008). Cabeças e corpos, adultos e crianças: cadê o movimento e quem separou tudo isso?. Revista Eletrônica de Educação, 2(2), 92-105.

Young, I. (1997). Intersecting voices: dilemas of gender, political philosophy, and policy. Princeton, NJ: Princeton University Press. 